\title{
Produtividade de seis cultivares de maracujazeiro-azedo durante três anos em Vargem Bonita, $\mathrm{DF}^{(1)}$
}

\author{
Karina Tittoto Melo(2), Ivo Manica ${ }^{(2)}$ e Nilton Tadeu Vilela Junqueira( ${ }^{(3)}$
}

\begin{abstract}
Resumo - Avaliou-se a produtividade de cultivares de maracujazeiro-azedo (Passiflora edulis), com vistas à seleção de um material mais produtivo nas condições do Distrito Federal para frutos destinados ao consumo in natura. As cultivares Maguari, CSB Marília, NJ3 Vermelho, CSB Marília x NJ3 Vermelho, Roxo Australiano e Seleção DF foram avaliadas durante três anos de produção, em Latossolo Vermelho-Amarelo, no sistema de espaldeira vertical. A cultivar Maguari apresentou porcentagem de germinação das sementes superior à das demais cultivares. A média da altura das plantas das cultivares Seleção DF e Roxo Australiano foi superior à das outras quatro cultivares. A cultivar Maguari apresentou o maior vigor vegetativo durante os três anos de experimento, e o menor número de plantas perdidas por declínio da cultura. A cultivar CSB Marília foi a mais precoce e a primeira a produzir frutos. Na primeira safra, as cultivares CSB Marília, CSB Marília x NJ3 Vermelho, Roxo Australiano e Seleção DF foram as mais produtivas. No segundo ano de colheita, as seis cultivares apresentaram alta produtividade, destacando-se a cultivar Seleção DF, que produziu $50 \mathrm{t} / \mathrm{ha}$. No terceiro ano de produção, em que ocorreu um declínio considerável, a cultivar Maguari apresentou a maior produtividade. Na produção média dos três anos, as seis cultivares mostraram-se superiores em produtividade aos resultados já conhecidos da pesquisa no Brasil.
\end{abstract}

Termos para indexação: Passiflora edulis, variedades, cerrados, rendimento de culturas.

\section{Yield of six cultivars of passion fruits along of three years in Vargem Bonita county, Federal District, Brazil}

\begin{abstract}
The productivity of sour-passionfruit cultivars was evaluated for the purpose of obtaining productive material adapted to the Federal District conditions for consumption in natura. Maguari, CSB Marília, NJ3 Vermelho, CBS Marília x NJ3 Vermelho, Roxo Australiano and Seleção DF cultivars were evaluated during three production years in a Red-Yellow Latosol soil in the vertical stake system. Maguari presented higher seed germination rate than that of the other cultivars. The medium plant height of Seleção DF and Roxo Australiano was superior to that of the other four cultivars. Maguari showed the greatest vegetative vigor during the three-year experiment and the mindest number of lost plants due to crop decay. CSB Marília was the most precocious and the first cultivar to produce fruits. By the first harvest, CSB Marília, CSB Marília x NJ3 Vermelho, Roxo Australiano and Seleção DF were the most yielding. In the second year of harvesting, all six cultivars showed high productivity, and Seleção DF surpassed all the other cultivars, with 50 ton/ha. In the third year, in which a considerable decay occurred, Maguari presented the maximum productivity. In the three-year of production, the six cultivars showed to be superior in productivity in relation to the results of all other research ever seen in Brazil.
\end{abstract}

Index terms: Passiflora edulis, varieties, savannas, crop yields.

\footnotetext{
(1) Aceito para publicação em 6 de novembro de 2000. Extraído da Dissertação de Mestrado, apresentada pelo primeiro autor à Universidade de Brasília (UnB), Brasília, DF.

(2)UnB, Dep. de Agronomia, Campus Darcy Ribeiro, Caixa Postal 04508, Asa Norte, CEP 70910-970 Brasília, DF. E-mail: jemaraujo@bol.com.br, manica@unb.br

${ }^{(3)}$ Embrapa-Centro de Pesquisa Agropecuária dos Cerrados, BR-020, km 18, Caixa Postal 700023, CEP 73301-000 Planaltina, DF. E-mail: junqueir@cpac.embrapa.br
}

\section{Introdução}

Nas últimas décadas, a cultura do maracujazeiro, tanto o maracujazeiro-amarelo (Passiflora edulis Sims f. flavicarpa Deg.), quanto o maracujazeiroroxo (Passiflora edulis Sims), vem atingindo significativa importância econômica no Brasil e no mercado internacional de frutas tropicais. Cerca de $65 \%$ 
da produção brasileira é destinada ao mercado interno de frutas frescas, e o restante, à produção de sucos concentrados para o mercado externo (Rossi, 1998).

O Brasil, a Colômbia, Sri Lanka, Peru e Equador são os maiores exportadores de suco concentrado de maracujá (Ruggiero et al., 1995). A produção mundial de maracujá concentra-se principalmente na América do Sul, onde o Brasil é o principal produtor, com 405.869 t no ano de 1995, em uma área de 38.522 ha, evidenciando a sua importância no mercado interno nos diferentes segmentos de consumo (Produção vegetal, 1996).

A região Nordeste do Brasil é a principal produtora, responsável por 40,04\% (162.504 t) da produção total, seguida pelas regiões Norte, Sudeste, Centro-Oeste e Sul, com as quantidades de 130.931, $96.553,9.056$ e $6.825 \mathrm{t}$, respectivamente. Na região Centro-Oeste, a cultura do maracujá ganhou expressão após a criação do complexo agroindustrial do Triângulo Mineiro e Goiânia, que absorve cerca de $40 \%$ da produção brasileira. O Distrito Federal se apresenta como o segundo produtor, responsável por $10,20 \%$ da produção do Centro-Oeste, na quantidade de 924 t em 1995, superado apenas pelo Estado de Goiás.

O maracujazeiro é cultivado principalmente por pequenos agricultores do Distrito Federal, com a média de 3 a 5 ha por propriedade, mostrando que a cultura pode ser uma boa alternativa econômica para os produtores, contribuindo para valorizar o trabalho e melhorar o seu padrão de vida (EMATERDF, 1997).

O Brasil possui excelentes condições ecológicas para o cultivo do maracujazeiro, mas a produtividade, de modo geral, ainda é baixa. Esse fato deve-se principalmente à falta de informações técnico-científicas e ao baixo nível tecnológico dos produtores no manejo da cultura pré e pós-colheita.

As cultivares propagadas atualmente têm as seguintes características: são plantas precoces; muito vigorosas; com razoável tolerância à bacteriose e à antracnose; alta produtividade/ha e maior resistência à seca (Piza Júnior, 1998).

Diante dos problemas acarretados por doenças, nas regiões semi-áridas, a cultura do maracujazeiro em breve deverá ser considerada como cultura anual, fato que já vem ocorrendo com alguns produtores mais tecnificados, que adensam a sua área de cultivo, chegando a plantar 2.300 plantas/ha, visando atingir maior produtividade e nas quantidades de 10 a $20 \mathrm{t} / \mathrm{ha}$ na entressafra que ocorre de agosto a novembro, quando os frutos têm melhores preços no mercado (São José et al., 1997).

O objetivo deste trabalho foi avaliar a produtividade de seis cultivares de maracujazeiro, visando à seleção de um material de maior rendimento por planta e hectare, adaptado às condições do Distrito Federal, para frutos destinados ao consumo em forma natural.

\section{Material e Métodos}

O experimento foi conduzido na Fazenda Água Limpa, da Universidade de Brasília, situada na parte sul do Distrito Federal, com uma latitude de $16^{\circ} \mathrm{Sul}$, longitude de $48^{\circ}$ Oeste e $1.100 \mathrm{~m}$ de altitude. A área utilizada para o experimento foi de 0,25 ha.

O delineamento experimental foi o de blocos casualizados, com o plantio de seis cultivares, em quatro repetições, e cada parcela constituída de dez plantas úteis e com uma bordadura externa para todas as repetições.

As cultivares avaliadas foram: Maguari (seleção de sementes obtidas junto às indústrias Maguari, Araguari, MG), CSB Marília (seleção da Cooperativa Sul Brasil, Marília, SP), NJ3 Vermelho (híbrido entre Passiflora edulis Sims f. flavicarpa Deg. x Passiflora edulis cf. f. rubra ou maracujá sangüínea ou perobinha amazônico, nativo no Juruá, AM), CSB Marília x NJ3 Vermelho (híbrido de polinização controlada das duas cultivares), Roxo Australiano (seleção australiana de Passiflora edulis Sims, utilizada para consumo ao natural, introduzido no Brasil no final de 1987) e Seleção DF (selecionada no Distrito Federal, com tolerância à morte precoce, resistente à seca da rama, à bacteriose, e com alta produtividade nas condições do Distrito Federal, mesmo sem a irrigação).

As sementes das seis cultivares estiveram armazenadas por um período aproximado de doze meses. Para a produção das mudas, utilizou-se solo da superfície adubado, com $15 \mathrm{~L} / \mathrm{m}^{3}$ de esterco de ovinos, $500 \mathrm{~g} / \mathrm{m}^{3}$ de superfosfato simples, $500 \mathrm{~g} / \mathrm{m}^{3}$ de cloreto de potássio e $2 \mathrm{~kg} / \mathrm{m}^{3}$ de calcário dolomítico. Este solo foi colocado em recipientes de plástico de $18 \times 30 \mathrm{~cm}$, e as sementes foram colocadas à profundidade em torno de $1 \mathrm{~cm}$, no dia $29 \mathrm{de}$ março de 1995. A germinação foi acompanhada semanalmente, e as mudas ficaram em casa de vegetação até apresentarem a primeira gavinha, com tamanho aproximado 
de $20 \mathrm{~cm}$; quando prontas, foram transplantadas para covas definitivas no campo.

O desenvolvimento das cultivares foi acompanhado semanalmente, para avaliar o vigor, que foi determinado através de medição da altura das plantas, cinco dias antes do desponte.

O solo onde foi instalado o experimento é um Latossolo Vermelho-Amarelo, fase argilosa, profundo, com boa drenagem, baixa fertilidade natural, apresentando as seguintes características: $\mathrm{Ca}, 5 \mathrm{mmol}_{\mathrm{c}} / \mathrm{dm}^{3} ; \mathrm{Mg}, 1 \mathrm{mmol}_{\mathrm{c}} / \mathrm{dm}^{3}$; $\mathrm{K}, 0,6 \mathrm{mmol}_{\mathrm{c}} / \mathrm{dm}^{3}$; acidez total, $45 \mathrm{mmol}_{\mathrm{c}} / \mathrm{dm}^{3}$; $\mathrm{Al}$, 2,0 $\mathrm{mmol}_{\mathrm{c}} / \mathrm{dm}^{3}$; S, $6,6 \mathrm{mmol}_{\mathrm{c}} / \mathrm{dm}^{3}$; CTC, 51,6 $\mathrm{mmol}_{\mathrm{c}} / \mathrm{dm}^{3}$; saturação de bases, $12,7 \%$;, 4 mg/dm³ ${ }^{3}$ matéria orgânica, 29,2 g/kg e pH em água 5,2. Após a análise, o solo sofreu correção com calcário dolomítico e foi preparado com uma aração a $30 \mathrm{~cm}$ de profundidade e duas gradagens, para nivelar o terreno e incorporar o calcário.

Na área utilizada, de 0,25 ha, o espaçamento adotado para a marcação das covas foi de $3 \mathrm{~m}$ entre linhas por $2,5 \mathrm{~m}$ entre plantas, correspondente a 1.333 plantas/ha. A cova de plantio foi aberta manualmente, medindo $0,60 \times 0,60 \times$ 0,60 m. Após a abertura das covas, foi feita uma mistura da terra de superfície com os adubos exigidos para o plantio da cultura do maracujazeiro. Feita a mistura, colocouse a terra adubada no fundo da cova. A adubação foi baseada na recomendação das Indústrias Maguari, localizada em Araguari, MG, sendo utilizados, por cova, $20 \mathrm{~L}$ de esterco de ovinos, $350 \mathrm{~g}$ de termofosfato Yoorin, $350 \mathrm{~g}$ de superfosfato simples, $1.000 \mathrm{~g}$ de calcário dolomítico e $50 \mathrm{~g}$ de FTE BR-12.

O plantio das mudas no campo foi efetuado cerca de três meses depois, em 30 de junho de 1995, retirando-se as mudas dos recipientes de plástico e colocando-as nas covas definitivas, sobre a terra adubada, fechando-se a cova com a terra de subsolo, que fora retirada para a abertura dessa cova.

Para a sustentação das plantas, foi feita uma espaldeira vertical, com mourões a espaços de $5 \mathrm{~m}$, e um fio de arame a $2 \mathrm{~m}$ de altura. Em cada cova, colocou-se um tutor (bambu) ao lado da muda de maracujazeiro, para conduzir o caule do ramo principal, até atingir o fio de arame, e então foi despontado, deixando-se um ramo secundário desenvolvendo-se horizontalmente para cada lado da planta sobre o fio de arame até encontrarem o ramo secundário da planta seguinte, quando, então, foram despontados novamente, para a condução dos ramos terciários. Os ramos terciários foram conduzidos verticalmente em forma de cortina, sendo podados cerca de $20 \mathrm{~cm}$ antes de atingirem a superfície do solo.

Além da adubação na cova de plantio, foram realizadas outras em forma de cobertura. Aplicou-se em forma de cobertura a $40 \mathrm{~cm}$ da haste principal do maracujazeiro, $70 \mathrm{~g}$ de sulfato de amônio, em setembro de 1995 e $150 \mathrm{~g}$ de sulfato de amônio, em novembro de 1995.

Na primeira safra, aplicou-se em forma de cobertura, a $60 \mathrm{~cm}$ da haste principal do maracujazeiro, $225 \mathrm{~g}$ de sulfato de amônio, $200 \mathrm{~g}$ de cloreto de potássio e $50 \mathrm{~g}$ de FTE BR-12, em fevereiro de 1996; $400 \mathrm{~g}$ de sulfato de amônio e $300 \mathrm{~g}$ de cloreto de potássio, em abril de 1996; nos meses de setembro e dezembro de 1996 e março de 1997 (segunda safra), foram aplicados $400 \mathrm{~g}$ de sulfato de amônio, $400 \mathrm{~g}$ de superfosfato simples e $300 \mathrm{~g}$ de cloreto de potássio. Em setembro e dezembro de 1997, $300 \mathrm{~g}$ de sulfato de amônio, $300 \mathrm{~g}$ de superfosfato simples e $250 \mathrm{~g}$ de cloreto de potássio, e em abril de 1998 (terceira safra), realizou-se a última adubação de cobertura, com $250 \mathrm{~g}$ de sulfato de amônio, $250 \mathrm{~g}$ de superfosfato simples e $200 \mathrm{~g}$ de cloreto de potássio.

As plantas foram irrigadas por aspersão apenas no período de instalação da cultura no campo, nos meses de julho a setembro de 1995. O clima da região é do tipo AW, caracterizado por chuvas concentradas no verão, de outubro a abril, e invernos secos, de maio a setembro. A precipitação pluvial no período de junho de 1995 a setembro de 1996 foi de $1.295,78 \mathrm{~mm}$ (1a safra); no período de outubro de 1996 a julho de 1997, foi de 1.696,99 mm (2a safra), e de agosto de 1997 a setembro de 1998, de $1.452,62 \mathrm{~mm}$ (3a safra), mas a distribuição das chuvas não foi regular, chegando a níveis muito baixos no período de junho a agosto; houve precipitações intensas nos meses de janeiro a março, durante os três anos de produção.

Durante a condução do experimento, a média das temperaturas mínimas foi de $14,8^{\circ} \mathrm{C}$, e a temperatura mínima absoluta atingiu $8^{\circ} \mathrm{C}$ em julho de 1996 . O número de horas diárias de sol variou entre 11,3 no mês de junho e 12,9 no mês de dezembro, na região de Brasília (latitude de $\left.14^{\circ} \mathrm{Sul}\right)$.

A produção de frutos das plantas em qualidade e quantidade foram o resultado das técnicas de cultivo apenas com a polinização natural, sem a utilização da polinização artificial durante todo o período do experimento. Através de acompanhamentos semanais desde o início do florescimento e da frutificação foi observado, além do aspecto vegetativo, a precocidade das plantas de todos os tratamentos.

As colheitas foram realizadas regularmente apenas de frutos caídos no chão, quando estavam completamente maduros e soltavam-se da planta. Esta catação foi realizada duas vezes por semana, para evitar as perdas de peso, murchamento, e para diminuir a ocorrência de podridões nos períodos chuvosos. O controle dos frutos maduros foi realizado de fevereiro de 1996 a setembro de 1998. Após 
cada colheita, os frutos eram levados para um armazém, onde eram pesados, contados e lavados.

Posteriormente, com base na produção por planta, foi realizado o cálculo da produtividade em t/ha, base para poder realizar as análises comparativas das médias, as quais foram feitas através do teste de Tukey a 5\% de probabilidade.

\section{Resultados e Discussão}

A germinação das sementes de todas as cultivares, com exceção da NJ3 Vermelho, teve início aos 14 dias após a semeadura, e se estendeu até aos 28 dias após a semeadura. Estes dados estão de acordo com Manica et al. (1994), que relata um período de germinação de três a quatro semanas após a semeadura.

A cultivar Maguari apresentou porcentagem de germinação das sementes superior à das outras cinco cultivares (Tabela 1).

Piza Júnior (1991) apresentou dados de germinação após um ano de armazenamento entre $23 \%$ e $36 \%$, enquanto Manica et al. (1994) cita resultados de germinação de sementes armazenadas até quatro semanas, entre $70 \%$ e $90 \%$, e Oliveira et al. (1993), em experimento com diferentes tipos de substratos e bandejas, encontraram, após 20 dias de semeadura, uma germinação em torno de $81 \%$.

Os resultados obtidos para a germinação da cultivar Roxo Australiano esteve de acordo com os dados de Piza Júnior (1991), enquanto as demais cultivares estiveram próximas dos resultados obtidos por Oliveira et al. (1993) e Manica et al. (1994).

A variação da germinação encontrada no presente trabalho ocorreu em virtude do armazenamento das sementes pelo período aproximado de 12 meses, afetando principalmente a cultivar Roxo Australiano, a que apresentou menor porcentagem de germinação (Tabela 1).

No período inicial do crescimento das mudas no campo, aos 90 dias após a semeadura, avaliaram-se as médias de altura das plantas, onde verificou-se que as cultivares Seleção DF e Roxo Australiano foram superiores às outras quatro cultivares estudadas.

São José et al. (1994) obtiveram mudas em substrato de esterco de curral, 59 dias após semeadura, com altura entre 64,8 e $75,34 \mathrm{~cm}$, enquanto
Almeida et al. (1991) registraram, 90 dias após semeadura, plantas com $84,0 \mathrm{~cm}$ de altura.

Comparando-se com os resultados anteriores, pode-se observar que as mudas das seis cultivares atingiram altura superior à das médias encontradas na literatura. Este fato ocorreu devido ao próprio material genético adaptado às condições da região, à temperatura ideal na época da semeadura, à irrigação, ao tipo de solo, e à adubação utilizada nas covas e tratos culturais mais adequados.

O primeiro florescimento teve início entre o final de outubro e início de novembro de 1995, decorridos cerca de sete meses após a semeadura, e quatro meses após o plantio definitivo em campo. Em 19 de dezembro de 1995, o florescimento atingiu 97,5\% das plantas das cultivares NJ3 Vermelho e Maguari, e $100 \%$ nas outras quatro cultivares.

Em 8 de fevereiro de 1996, teve início a colheita de frutos maduros na cultivar Maguari em 2,5\% das plantas, e as outras cinco cultivares apresentaram as seguintes porcentagens de frutos maduros: Roxo Australiano, 25\%; CSB Marília, 20\%; CSB Marília x NJ3 Vermelho, 17,5\%; Seleção DF, 15\%, e NJ3 Vermelho, 7,5\%.

A colheita dos frutos maduros ocorreu cerca de 70 dias após a diferenciação floral (antese), nas seis cultivares estudadas. A primeira colheita iniciou-se em 29 de janeiro de 1996 nas cultivares CSB Marília x NJ3 Vermelho; Roxo Australiano e Seleção DF, que apresentaram 7,5\% das plantas com frutos maduros, sendo que as outras três cultivares ainda não apresentaram, nesta data, frutos maduros.

Conforme a produção (Tabela 2), o florescimento diminuiu significativamente à medida que houve de-

Tabela 1. Porcentagem de germinação aos 30 dias e altura das plantas aos 90 dias após semeadura, de seis cultivares de maracujazeiro-azedo ${ }^{(1)}$.

\begin{tabular}{lcc}
\hline Cultivar & $\begin{array}{c}\text { Germinação } \\
(\%)\end{array}$ & $\begin{array}{c}\text { Altura } \\
(\mathrm{m})\end{array}$ \\
\hline CSB Marília & $74 \mathrm{~b}$ & $1,50 \mathrm{c}$ \\
CSB Marília x NJ3 Vermelho & $62 \mathrm{c}$ & $1,72 \mathrm{~b}$ \\
Roxo Australiano & $41 \mathrm{~d}$ & $1,77 \mathrm{a}$ \\
Seleção DF & $66 \mathrm{bc}$ & $1,83 \mathrm{a}$ \\
Maguari & $94 \mathrm{a}$ & $1,71 \mathrm{~b}$ \\
NJ3 Vermelho & $70 \mathrm{~b}$ & $1,40 \mathrm{c}$ \\
\hline
\end{tabular}

(1)Valores seguidos pela mesma letra na coluna não diferem significativamente entre si pelo teste de Tukey a $5 \%$ de probabilidade. 
créscimo na precipitação pluvial e na temperatura, durante os meses de junho a agosto, retomando o florescimento a partir do mês de setembro, à medida que a precipitação pluvial voltou a ocorrer e a temperatura ambiente começou a subir.

No Estado de São Paulo, Urashima (1985) registrou a colheita 84 dias após a antese. Neves et al. (1999) registraram um período médio, desde a antese até a colheita dos frutos maduros, de 65,7 e 105,4 dias, respectivamente, nos florescimentos ocorridos nos meses de janeiro e abril. Veras (1997) conseguiu frutos de maracujá-azedo 69,3 dias após a antese, nas condições do Distrito Federal. Meinke \& Karnatz (1990) relacionaram os dias após a antese (DAA) com a temperatura ambiente em híbridos de maracujá-roxo, e concluíram que houve um ciclo que variou de 66,7 dias com a temperatura de $25^{\circ} \mathrm{C}$ e de 93,6 dias com a temperatura de $18^{\circ} \mathrm{C}$. Esta hipótese é válida para a avaliação das seis cultivares em questão, ressaltando, todavia, uma grande influência da radiação solar e não sendo descartado o caráter genético das plantas.

As cultivares CSB Marília, CSB Marília x NJ3 Vermelho, Roxo Australiano e Seleção DF apresentaram produtividades semelhantes às da cultivar Maguari, e superior à NJ3 Vermelho, em t/ha na primeira safra (Tabela 2).

Em diversos locais e condições de cultivo, na primeira safra do maracujazeiro a produtividade tem sido de 9,3 t/ha, em média, obtidos por Kist et al. (1995), em Porto Lucena, RS. São José et al. (1997) produziram entre 10 e 20 t/ha nas diversas cultivares de maracujazeiro-azedo, enquanto a média obtida por Ritzinger et al. (1987), em Viamão, RS, esteve em torno de $23 \mathrm{t} /$ ha na primeira safra de maracujazeiroamarelo, e Lins et al. (1984) encontraram produtividade entre 12,0 e 27,0 t/ha, concordando, assim, com a produtividade encontrada na cultivar NJ3 Vermelho neste experimento na primeira safra, sendo portanto a cultivar menos produtiva entre as seis testadas. Carvalho et al. (1999) conseguiram 36,3 t/ha, com espaçamento de 2,5 × 3,0 m, o mesmo utilizado para as seis cultivares estudadas neste experimento, concordando, portanto, com os resultados obtidos na CSB Marília, CSB Marília x NJ3 Vermelho, Roxo Australiano, Seleção DF e Maguari.

De acordo com os resultados citados anteriormente, pode-se observar que quatro autores em diferen- tes condições de cultivo apresentaram resultados bastante inferiores aos obtidos pelas cultivares CSB Marília, CSB Marília x NJ3 Vermelho, Roxo Australiano, Seleção DF e Maguari, enquanto Carvalho et al. (1999) apresentaram resultados em torno de 36,3 t/ha e Lins et al. (1984) aproximaram-se dos resultados obtidos pela cultivar NJ3 Vermelho, com cerca de 27,0 t/ha. Como as seis cultivares foram plantadas em junho de 1995, as plantas tiveram apenas quatro meses para acumularem reservas, o que, provavelmente, fez com que os frutos produzidos apresentassem tamanhos menores. Caso o plantio tivesse sido efetuado em janeiro, as plantas teriam acumulado reservas, e os frutos poderiam ser maiores, do que provavelmente resultaria uma produtividade maior.

As seis cultivares durante a segunda safra apresentaram uma produção relevante em t/ha e não diferiram estatisticamente entre si (Tabela 2).

Alguns trabalhos (Lins et al., 1984; Ritzinger et al., 1987) conseguiram resultados, na segunda safra, entre 9,0 e 18,1 t/ha, abaixo, portanto, dos resultados observados nas seis cultivares avaliadas neste trabalho. Veras (1997) obteve 29,7 t/ha na segunda safra, com a cultivar CSB Marília no Distrito Federal. Carvalho et al. (1999) conseguiram 50,2 t/ha, resultado muito próximo do alcançado com a cultivar Seleção DF, que chegou a 50,33 t/ha; porém, Carvalho et al. (1999), para obter 50,2 t/ha, utilizaram espaçamento ultra-denso de 1,0 x 2,5 m, apresentando um número muito maior de plantas/ha, enquanto as seis cultivares avaliadas foram plantadas com um espaçamento de $2,5 \times 3,0 \mathrm{~m}$.

O segundo ano apresentou melhores resultados de produtividade, pois as plantas estavam com 1,5 anos de idade e tiveram tempo para repor as reservas e apresentar maior número de ramos frutíferos. Também a temperatura, a luminosidade e a precipitação foram mais favoráveis à cultura, alcançando resultados que se destacaram sobre os resultados conseguidos por outros trabalhos que utilizaram espaçamento $2,5 \times 3,0 \mathrm{~m}$.

Após a segunda safra, realizou-se uma poda drástica no mês de agosto de 1997, para retirada dos ramos doentes ou secos e dos que tocavam o solo. Esta poda foi feita em um período de repouso; mas a planta não apresentou boa recuperação, pois estava entran- 
do no terceiro ano de produção, pois normalmente a cultura do maracujazeiro, em climas tropicais, já está entrando em declínio. As plantas voltaram a produzir somente no mês de novembro de 1997.

$\mathrm{Na}$ terceira safra (1998) a cultivar Maguari foi semelhante às cultivares CSB Marília x NJ3 Ver- melho, Seleção DF e CSB Marília, e superior às demais (Tabela 2).

Na terceira safra, Accorsi et al. (1992) conseguiram apenas 2,1 t/ha após poda de 1,5 $\mathrm{m}$ de altura nas cultivares com que trabalharam, dada a ocorrência de geadas na região do experimento no terceiro ano

Tabela 2. Distribuição da produtividade (t/ha) de seis cultivares de maracujazeiro, ao longo das safras de $1996,1997 \mathrm{e}$ $1998^{(1)}$

\begin{tabular}{|c|c|c|c|c|c|c|}
\hline Mês & CSB Marília & $\begin{array}{l}\text { CSB Marília x } \\
\text { NJ3 Vermelho }\end{array}$ & Roxo Australiano & Seleção DF & Maguari & NJ3 Vermelho \\
\hline & \multicolumn{6}{|c|}{1996} \\
\hline Fevereiro & 2,440 & 1,320 & 1,590 & 1,920 & 0,810 & 0,990 \\
\hline Março & 10,780 & 10,220 & 9,290 & 10,210 & 7,370 & 7,700 \\
\hline Abril & 5,440 & 6,160 & 6,700 & 5,210 & 5,580 & 3,830 \\
\hline Maio & 4,960 & 4,570 & 2,990 & 4,180 & 4,910 & 3,580 \\
\hline Junho & 5,130 & 4,860 & 4,110 & 4,570 & 4,290 & 3,300 \\
\hline Julho & 3,010 & 3,910 & 4,110 & 3,110 & 2,620 & 1,520 \\
\hline Agosto & 1,910 & 2,950 & 2,640 & 1,990 & 1,570 & 1,080 \\
\hline Setembro & 0,352 & 0,273 & 0,235 & 0,175 & 0,057 & 0,180 \\
\hline Outubro & 0,073 & 0,029 & 0,060 & 0,014 & 0,002 & 0,013 \\
\hline Novembro & 1,655 & 1,621 & 1,530 & 1,844 & 1,127 & 2,501 \\
\hline Dezembro & 4,834 & 3,143 & 2,519 & 3,977 & 2,383 & 2,446 \\
\hline \multirow[t]{2}{*}{ Total } & $40,58 \mathrm{a}$ & $39,06 \mathrm{a}$ & $35,77 \mathrm{a}$ & $37,20 \mathrm{a}$ & $30,72 \mathrm{ab}$ & $27,14 b$ \\
\hline & \multicolumn{6}{|c|}{1997} \\
\hline Janeiro & 8,862 & 7,182 & 8,530 & 9,171 & 5,558 & 5,540 \\
\hline Fevereiro & 8,033 & 8,310 & 7,483 & 8,060 & 6,423 & 7,227 \\
\hline Março & 8,007 & 8,987 & 7,130 & 8,633 & 7,150 & 4,573 \\
\hline Abril & 6,180 & 8,267 & 7,233 & 7,610 & 3,697 & 6,440 \\
\hline Maio & 9,530 & 9,013 & 6,873 & 8,030 & 6,530 & 6,637 \\
\hline Junho & 4,483 & 4,873 & 2,860 & 4,497 & 7,507 & 4,107 \\
\hline Julho & 1,222 & 1,709 & 1,751 & 2,020 & 4,049 & 2,261 \\
\hline Novembro & 0,305 & 0,094 & 0,138 & 0,358 & 0,037 & 0,423 \\
\hline Dezembro & 0,872 & 1,094 & 0,654 & 1,948 & 0,396 & 1,840 \\
\hline \multirow[t]{2}{*}{ Total } & $47,49 \mathrm{a}$ & $49,53 \mathrm{a}$ & $42,65 a$ & $50,33 a$ & $41,35 \mathrm{a}$ & $39,05 \mathrm{a}$ \\
\hline & \multicolumn{6}{|c|}{1998} \\
\hline Janeiro & 1,219 & 1,656 & 1,049 & 1,749 & 0,717 & 0,990 \\
\hline Fevereiro & 2,893 & 3,942 & 2,633 & 4,440 & 4,391 & 1,422 \\
\hline Março & 1,536 & 2,157 & 0,686 & 1,198 & 1,706 & 0,647 \\
\hline Abril & 1,760 & 2,322 & 0,994 & 1,886 & 2,542 & 1,116 \\
\hline Maio & 0,874 & 0,935 & 0,429 & 0,749 & 1,788 & 0,512 \\
\hline Junho & 0,127 & 0,281 & 0,051 & 0,230 & 0,560 & 0,111 \\
\hline Julho & 0,107 & 0,098 & 0,013 & 0,071 & 0,142 & - \\
\hline Agosto & 0,087 & 0,071 & 0,031 & 0,191 & 0,245 & 0,156 \\
\hline Setembro & 0,100 & 0,069 & 0,008 & 0,089 & 0,113 & 0,011 \\
\hline Total & $8,70 \mathrm{abc}$ & $11,53 \mathrm{ab}$ & $5,89 \mathrm{bc}$ & $10,60 \mathrm{abc}$ & $12,20 \mathrm{a}$ & $4,97 \mathrm{c}$ \\
\hline Total geral & $96,97 \mathrm{a}$ & $100,12 \mathrm{a}$ & $84,31 \mathrm{ab}$ & $98,13 \mathrm{a}$ & $84,27 \mathrm{ab}$ & $71,16 b$ \\
\hline Média geral & $32,32 \mathrm{a}$ & $33,37 \mathrm{a}$ & $28,10 \mathrm{ab}$ & $32,71 \mathrm{a}$ & $28,09 \mathrm{ab}$ & $23,72 b$ \\
\hline
\end{tabular}

(1) Valores seguidos pela mesma letra na linha não diferem significativamente entre si pelo teste de Tukey a 5\% de probabilidade. 
de produção; Lins et al. (1984) encontraram cultivares produzindo de 7,0 a 28,0 t/ha no terceiro ano, e Ritzinger et al. (1987) conseguiram entre 19,8 e $21,6 \mathrm{t} / \mathrm{ha}$. Os resultados encontrados por Lins et al. (1984) estiveram próximos aos resultados encontrados nas seis cultivares avaliadas, variando de 4,97 t/ha na NJ3 Vermelho, até 12,20 t/ha na cultivar Maguari, enquanto os obtidos por Ritzinger et al. (1987) foram superiores, provavelmente em virtude de os experimentos terem sido instalados em regiões de clima temperado, onde a produção apresenta apenas um pico de produção no período mais quente do ano, havendo tempo para as plantas acumularem as reservas, o que não ocorre em regiões de clima tropical, como a de Brasília. Carvalho et al. (1999) obtiveram produtividade média em dois anos de cultivo de 34,6 t/ha devido a aplicação de $434 \mathrm{~g}$ de $\mathrm{K} /$ planta/ano.

A baixa produtividade no terceiro ano de produção ocorreu devido ao envelhecimento da planta, que por ter sido cultivada em região de clima tropical, apresentou produção contínua, não havendo tempo para que as plantas acumulassem reservas em decorrência das altas produtividades nos anos anteriores e a baixa capacidade ou ineficiência do sistema radicular para absorver nutrientes do solo para repor as reservas da planta. $\mathrm{O}$ intenso ataque de patógenos na cultura durante a terceira safra se deve em parte ao enfraquecimento das plantas pela falta de reservas, favorecendo ainda o aparecimento de doenças.

Quanto à produtividade total e produtividade média dos três anos, as cultivares CSB Marília x NJ3 Vermelho, Seleção DF e CSB Marília, foram estatisticamente semelhantes às cultivares Roxo Australiano e Maguari, e superiores à cultivar NJ3 Vermelho (Tabela 2).

Lopes et al. (1998) encontraram média de produção anual entre 11,99 e 14,32 t/ha, em experimentos com irrigação localizada, ficando bem abaixo dos resultados obtidos nas seis cultivares, enquanto Ritzinger et al. (1987) e São José et al. (1997) apresentaram produção variando entre 17,4 e 22,70 t/ha, próximo, portanto, aos valores encontrados na cultivar NJ3 Vermelho. Estes resultados estão bem acima da produtividade média do Distrito Federal, que, segundo a EMATER-DF (1997), está em torno de $10 \mathrm{t} / \mathrm{ha}$, podendo, assim, ser considerada excelente para o Distrito Federal e muito boa para a média brasileira, que está em torno de 12 t/ha (Carraro \& Cunha, 1994).

As médias alcançadas nas seis cultivares avaliadas (Tabela 2) foram bastante superiores, em comparação com os trabalhos citados anteriormente, e que apenas Carvalho et al. (1999) apresentaram resultados próximos aos encontrados no presente experimento. Pode-se verificar, ainda, que o segundo ano foi mais produtivo em todas as cultivares, e que no terceiro ano as cultivares já se encontravam em declínio, com produtividade bastante inferior.

Em todas as cultivares a concentração da produção ocorreu no período de janeiro a maio, durante os três anos de avaliação do experimento, apesar de produzirem praticamente durante o ano todo, e ficando sem produzir somente nos meses de setembro e outubro devido às baixas temperaturas e pouca precipitação ocorridas nos meses de junho e julho, fazendo com que não ocorresse a diferenciação floral (antese), e, conseqüentemente, não produzisse. Apesar da não-utilização da irrigação e da polinização artificial, as seis cultivares apresentaram excelentes resultados. Essa superioridade também pode ser devida ao material genético mais adaptado às condições de Cerrado.

A cultivar Maguari apresentou maior vigor vegetativo durante os três anos de experimento, apresentando menor número de plantas perdidas por declínio da cultura; por outro lado, foi uma das cultivares que apresentou a mais baixa produtividade. Dessa forma, acredita-se que esta cultivar, por produzir menos, acumulou mais reserva nos ramos e teve maior longevidade e resistência às doenças.

A cultivar NJ3 Vermelho foi a menos produtiva e a mais suscetível às doenças, como verrugose, antracnose e seca-dos-ramos. No entanto, o híbrido entre essa cultivar e a cultivar CSB Marília foi bem superior aos seus progenitores, tanto no que diz respeito à produtividade total, como na longevidade da cultura, o que ocorreu possivelmente pelo efeito da heterose (vigor híbrido). Estes dados indicam o potencial dos híbridos na produção de cultivares comerciais.

Durante todo o período de condução do experimento, a temperatura não ficou abaixo dos $4^{\circ} \mathrm{C}$, o que poderia danificar a planta de forma irrecuperável, 
segundo Piza Júnior (1991). O número de horas de brilho de sol esteve dentro do exigido pela cultura, que é de mais de 11 horas/dia, segundo Teixeira (1995), o que comprova que as condições encontradas no Distrito Federal são favoráveis para o cultivo do maracujazeiro, mostrando-se uma boa alternativa para os pequenos produtores da região do Distrito Federal.

\section{Conclusões}

1. A cultivar Maguari apresenta porcentagem de germinação das sementes superior às demais cultivares, assim como maior vigor vegetativo e menor número de plantas perdidas por declínio da cultura.

2. A cultivar CSB Marília é a mais precoce.

3. Na primeira safra, as cultivares CSB Marília, CSB Marília x NJ3 Vermelho, Roxo Australiano e Seleção DF são as mais produtivas.

4. No segundo ano de colheita a cultivar Seleção DF chega a produzir até 50 t/ha.

5. No terceiro ano de produção há um declínio considerável na cultura do maracujazeiro-azedo.

\section{Referências}

ACCORSI, M. R.; MANICA, I.; GAMA, F. S. G.; KIST, H. G. K. Efeito da intensidade de poda sobre a produção do maracujá-amarelo em Eldorado do Sul, RS. Pesquisa Agropecuária Brasileira, Brasília, v. 27, n. 3, p. 463-472, mar. 1992.

ALMEIDA, L. P.; BOARETO, M. A. C.; SANTANA, R. G.; NASCIMENTO, G. M.; SOUZA, P. J. S.; SÃO JOSÉ, A. R. Estaquia, comportamento de maracujazeiro (Passiflora edulis Sims f. flavicarpa Deg.) propagados por vias sexual e vegetativa. Revista Brasileira de Fruticultura, Cruz das Almas, v. 13, n. 1, p. 153-156, 1991.

CARRARO, A. F.; CUNHA, M. M. Manual de exportação de frutas. Brasília: Maara/Frupex/IICA, 1994. 245 p.

CARVALHO, A. J. C.; MONNERAT, P. H.; MARTINS, D. P.; BERNARDO, S. Produtividade e qualidade do maracujazeiro amarelo em resposta à adubação potássica sob lâmina de irrigação. Revista Brasileira de Fruticultura, Cruz das Almas, v. 21, n. 3, p. 333-337, 1999.

EMATER-DF (Brasília, DF). Relatório de atividades 1997. Brasília, 1997. p. $6 ; 12 ; 21 ; 28$.
KIST, H. G. K.; MANICA, I.; BOARO, J. A. Efeito de seis espaçamentos de plantio na produção de maracujá-amarelo (Passiflora edulis f. flavicarpa Deg.) em Porto Lucena, RS. Pesquisa Agropecuária Gaúcha, Porto Alegre, v. 1, n. 1, p. 21-26, 1995.

LINS, W. B. A.; VAZ, R. L.; OGATA, T.; ROLIM, H. M. V. Introdução e avaliação de maracujá-amarelo em Goiás. In: CONGRESSO BRASILEIRO DE FRUTICULTURA, 7., 1984, Florianópolis. Anais... Florianópolis: Sociedade Brasileira de Fruticultura, 1984. p. 994-999.

LOPES, P. R. A.; ARAÚJO, J. A. C.; OLIVEIRA, J. C. Influência da irrigação localizada e cobertura do solo na produtividade do maracujazeiro (Passiflora edulis f. flavicarpa Deg.). In: MARACUJÁ: do plantio à colheita. Jaboticabal: Funep, 1998. p. 334.

MANICA, I.; FIORAVANÇO, J. C.; BARRADOS, C. I. N.; KIST, H. G. K.; KIST, H. Efeito de seis espaçamentos de plantio em quatro anos de produção do maracujazeiro-amarelo em Porto Lucena, RS. Pesquisa Agropecuária Brasileira, Brasília, v. 29, n. 11, p. 1715-1722, nov. 1994.

MEINKE, H.; KARNATZ, A. Influence of air and soil temperatures on grafted and self-rooted Passiflor hybrids. Scientia Horticulturae, Amsterdam, v. 43, n. 3/4, p. 237-246, July 1990.

NEVES, C. S. V. J.; CARVALHO, S. L. C.; NEVES, P. M. O. J. Porcentagem de frutificação, período de desenvolvimento dos frutos e unidades térmicas para maracujá amarelo. Revista Brasileira de Fruticultura, Cruz das Almas, v. 21, n. 2, p. 128-130, 1999.

OLIVEIRA, R. P.; SCIVITTARO, W. B.; VASCONCELOS, L. A. B. C. Avaliação de mudas de maracujazeiro em função do substrato e do tipo de bandeja. Scientia Agricola, Piracicaba, v. 50, n. 2, p. 261-266, 1993.

PIZA JÚNIOR, C. T. A cultura do maracujá na região Sudeste do Brasil. In: MARACUJÁ: do plantio à colheita. Jaboticabal: Funep, 1998. p. 20-48.

PIZA JÚNIOR, C. T. Cultura do maracujá. São Paulo: Coordenadoria de Assistência Técnica Integral, 1991. 71 p.

PRODUÇÃO vegetal. Anuário Estatístico do Brasil. Rio de Janeiro, v. 56, p. 36-37,1996.

RITZINGER, R.; MANICA, I.; RIBOLDI, J. Efeito do espaçamento de plantio sobre a produção do maracujazeiro-amarelo em Viamão, RS. Pesquisa Agropecuária Brasileira, Brasília, v. 22, n. 8, p. 809-815, ago. 1987.

ROSSI, A. D. Comercialização do maracujá. In: MARACUJÁ: do plantio à colheita. Jaboticabal: Funep, 1998. $388 \mathrm{p}$. 
RUGGIERO, C.; JOSÉ, A. R. S.; VOLPE, C. A.; zeiro. In: MARACUJÁ: produção e mercado. Vitória da OLIVEIRA, J. C. de; DURIGAN, J. F.; Conquista: Uesb, 1994. p. 41-48.

BAUMGARTNER, J. G.; SILVA, J. R. da; NAKAMURA, K.; FERREIRA, M. E. Maracujá para exportação: procedimentos de colheita e pós-colheita. Brasília: EmbrapaSPI, 1995. 36 p. (Série Publicações Técnicas Frupex, 12).

SÃO JOSÉ, A. R.; BRUCKNER, H.; MANICA, I.; HOFFMANN, M. Maracujá: temas selecionados: 1. Melhoramento, morte prematura, polinização, taxionomia. Porto Alegre: Cinco Continentes, 1997. 72 p.

SÃO JOSÉ, A. R.; SOUZA, I. V. B.; DUARTE FILHO, J.; LEITE, M. J. N. Formação de mudas de maracuja-

TEIXEIRA, C. G. Maracujá: a cultura. 2. ed. Campinas: Instituto de Tecnologia de Alimentos, 1995. 267 p.

URASHIMA, A. S. Aspectos fenológicos do maracujazeiro-amarelo (Passiflora edulis f. flavicarpa Deg.). Botucatu: Funep, 1985. 83 p. Dissertação de Mestrado.

VERAS, M. C. M. Fenologia, produção e caracterização físico-química dos maracujazeiros ácido (Passiflora edulis f. flavicarpa Deg.) e doce (Passiflora alata Dryand) nas condições de cerrado de Brasília, DF. Lavras: Ufla, 1997. 105 p. Dissertação de Mestrado. 